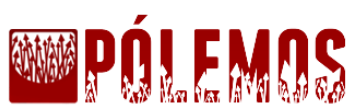

\section{DIÁLOGOS COM O EXPRESSIONISMO A PARTIR DE ADORNO E BENJAMIN}

\author{
Lennon Noleto \\ Graduando em Filosofia pela Universidade de Brasília - UnB
}

\begin{abstract}
RESUMO
Este texto retoma a questão do Expressionismo, que foi cara à crítica do início do século XX. Propõese uma análise a partir de Theodor Adorno e Walter Benjamin tendo como referências o diagnóstico sobre a arte de vanguarda e a relação entre obra e história. O objetivo é aproximar essas concepções à plástica do movimento. Posicionamentos da história da arte também são inseridos na discussão.
\end{abstract}

Palavras-chave: Adorno; Benjamin; Expressionismo; vanguarda.

\begin{abstract}
This text resumes the Expressionism case, which was useful to the art critics at the begging of the 20th century. It proposes an analysis of Theodor Adorno and Walter Benjamin, taking as reference the diagnosis over the avant-gard art and the relationship between artwork and history. The aim is an approach of these conceptions to the movement as visual arts. History of Art appointments are also included in the discussion.
\end{abstract}

Key words: Adorno; Benjamin; Expressionism; avant-gard.

\section{Sobre a arte de vanguarda}

As vanguardas do início do século $\mathrm{XX}$ trazem à luz o incontornável. A arte reconfigurou suas relações com o mundo e tornou seu acesso tortuoso, atordoante; trata-se de uma obra sintomática, o resultado da crise latente que, a partir desse momento, vem inevitavelmente à tona. A posição da arte na totalidade é uma abertura que se mostra também como negatividade. A existência da obra está em questão, bem como o discurso que a permeia.

Tais aspectos resumem, em linhas gerais, os problemas imanentes à obra de uma época cuja marca é a fragmentação. A arte de vanguarda se constituirá como um grande mosaico histórico; entre os espaços dessa montagem, está sua fragilidade. O movimento por ela realizado é o ápice de sua incompatibilidade com o mundo e consigo mesma. O que se chama "fim da arte" é o início de uma nova concepção através da qual ela se torna possível de várias formas. Consequentemente, a arte se perde em sua própria abertura, e esse seria o risco para sua existência.

Conforme aponta Adorno em sua Teoria Estética ${ }^{1}$, a obra alcançará sua legitimação em um constante processo de negação de sua origem. Através de seu próprio movimento, seu

1 ADORNO, Theodor Wiesengrund. Teoria Estética. Trad. Artur Mourão. Lisboa: Edições 70, 1970. 
"tornar-se" é o devir, de modo que sua incompatibilidade com o contingente - cujo grau máximo se encontra na vanguarda - é o caminho para sua própria identidade, um "outro" em relação ao mundo. A arte está na época de sua emancipação:

Na relação com a realidade empírica, a arte sublima o princípio, ali atuante do sense conservare, em ideal do ser-para-si dos seus testemunhos; segundo as palavras de Schönberg, pinta-se um quadro, e não o que ele representa. Toda obra de arte aspira por si mesma à identidade consigo, que, na realidade empírica, se impõe à força a todos os objetos, enquanto identidade com o sujeito e, deste modo, se perde. (ADORNO, 1982, p.15, grifo nosso)

O domínio da obra como negativo é consolidado. A criação de sua própria identidade aponta para o caráter não representacional e, em um primeiro momento, a figuração é superada. A afirmação de Schönberg evoca um aspecto da prática pictórica do início do século: o quadro não visa ser um equivalente aos objetos do mundo, mas uma referência a si mesmo. Esta situação faz com que esta obra não seja um modo de apresentação da experiência artística, porém a torna a própria experiência. Dir-se-ia que a emancipação é, portanto, um processo em que a obra carrega consigo o que vem a fragmentá-la. O programa sobre o qual os movimentos de vanguarda se sustentaram se baseia na liberdade que é, paradoxalmente, restrita em um todo e, além disso, uma liberdade que aflige a própria forma:

A perda do que se poderia fazer de modo não refletido o sem problemas não é compensada pela infinidade manifesta do que se tornou possível e que se propõe à reflexão. $\mathrm{O}$ alargamento das possibilidades revela-se em muitas dimensões como estreitamento. A extensão imensa do que nunca foi pressentido, a que se arrojavam os movimentos artísticos revolucionários cerca de 1910, não proporcionou a felicidade prometida pela aventura. Pelo contrário, o processo então desencadeado começou a minar as categorias pelas quais se tinha iniciado. (ADORNO, 1982, p.11)

O Expressionismo, em particular, desempenha um importante papel na crítica do início do século enquanto divisor de águas, respondendo ao problema posto. Os diversos debates que lhe são próprios atravessam não somente a questão artística, mas dizem respeito também à situação histórica. Em 1920, período marcante, pois a discussão é contemporânea ao próprio movimento, Adorno, em Expressionismo e conteúdo de verdade artístico: para uma crítica da nova poesia ${ }^{2}$, descreve o modo conflituoso pelo qual tal arte se dá. Como se possuísse um embate interno, sua relação com o mundo ocorre, em um primeiro olhar, de modo desorientado, criando-se ao mesmo tempo em que se move. A marca do

\footnotetext{
(Arte e Comunicação)

${ }^{2}$ ADORNO, Theodor W. Expressionismus und künstlicher Wahrhaftigkeit. In: Gesammelte Schriften. Frankfurt: Suhrkamp, 2004.
} 
Expressionismo seria realizar um movimento brusco que atravessa o real e, a partir deste, opera um corte meramente baseado na aparência. A autenticidade do gesto - ou ainda da "expressividade" - ocorre como um jogo em um vazio, um conflito superficial no qual as partes contrárias não estão sequer definidas. Observemos:

Em novas e estranhas formas apontadas, o Expressionismo é luta declarada. Todas as formas pelas quais ele irrompe se tornam um atrito contra a própria superfície, na qual ele rebenta como uma tocha flamejante. Como potência lançada contra as incontáveis resistências, ele não possui nenhuma orientação própria, mas se orienta no encontro com o mundo. Serenidade e reflexão lhe são estranhos. Onde ele possui coragem para ser esperto, precisa somente de sua esperteza para desagregar as formas contrárias. Os únicos pressupostos que lhe são definitivos pairam sobre a dúvida. (ADORNO, 2004, p.609, trad. nossa)

"A identidade estética deve defender o não-idêntico que a compulsão à identidade oprime na realidade" (ADORNO, 1982, p.15), ou seja, a esfera própria da arte lhe permite ser o "outro" que, em contradição com o plano empírico, completa-se, o que depende portanto de uma relação dialética entre obra e realidade ${ }^{3}$. A obra expressionista, porém, torna-se problemática na medida em que seu trânsito ocorre em apenas um dos extremos, de modo que a contradição necessária à legitimação da obra não se dá. Por consequência, seu movimento vaga no campo da subjetividade, o que gera uma criação artística indiferente, um simulacro que tem seu valor esvaziado:

A liberdade do Eu no Expressionismo ainda não se tornou lei. A desagregação das realidades é sintoma do último esvaziamento do conteúdo de verdade (Unwahraftigkeit), em cujas mãos o mundo subtraído se torna brinquedo à contrariedade, apoderando-se apenas em nome da dualidade, e não para averiguar o sentido daquela. $\mathrm{O}$ drama se torna uma simulação (Scheinvorgang), impacto de duplicações (Doppelgänger); o mundo pré-determinado dele advindo lhe é indiferente, ele se torna algo sem sentido. E a criação se degrada em desrespeito (Unehrfürchtigkeit), que, em algum ponto, fá-lo estéril e insensível. (ADORNO, 2004,,p.610)

Corroborando com o que o autor apontará décadas depois, a condição para que o conteúdo da obra se realize é o estranhamento entre as realidades, já que um pólo é dedutível de seu diferente. O "mero corte" ao qual o Expressionismo se propõe parece não realizar o confronto entre subjetividade e objetividade, a "dedução a partir de seu outro" a que Adorno se refere (ADORNO, 1982, p.13). Isso pode ser considerado uma falha imanente dado que, no processo natural de abertura conceitual da arte ao qual se assiste, a liberdade na criação

\footnotetext{
${ }^{3}$ Essa é a condição da qual a arte depende para constituir uma relação intersubjetiva.
} 
exigida pelos movimentos artísticos aponta para uma extirpação da definição em torno da obra, o que tornaria de certo modo controverso um engajamento através do programa ou manifesto segundo o qual a arte queira se sustentar.

Peter Bürger, em Teoria da Vanguarda ${ }^{4}$, desenha o processo que, por fim, resultará na emancipação alcançada pela obra na sociedade burguesa. Aponta-se que, inicialmente, tem-se a chamada "arte sacra", cuja função é ser instrumento de práticas religiosas (tais como as representações pictóricas de divindades); há, em seguida, o predomínio da "arte cortesã", quando o humano é cultuado, por exemplo, com retratos de autoridades e cenas do cotidiano social da monarquia; já no Romantismo, a subjetividade surge como caráter fundamental. Neste ponto, a obra adquire reflexibilidade, de modo a experienciar uma relação consigo mesma e desvinculada das práticas sociais, diferente de como ocorrera nos estágios anteriores:

Como objeto de culto, vale dizer, como objeto de representação, as obras de arte possuem uma finalidade de aplicação. Isso já não vale mais na mesma medida para a arte burguesa: a exibição da autocompreensão burguesa se dá num domínio da arte burguesa que se situa fora da práxis vital. O burguês, reduzido na sua práxis-vital a uma função parcial (ação ligada à racionalidade-voltada-com-respeitoa-fins); experimenta-se na arte como um "ser humano"; nela, ele consegue desenvolver a totalidade de suas capacidades, embora apenas sob a condição de que essa esfera permaneça divorciada da práxis vital. (BÜRGER, 2009, p. 104)

Trata-se da radicalização da premissa que a obra de arte deseja ser um "em-si". É válido ressaltar que esse movimento se relaciona com parte do percurso da história da arte descrito por $\mathrm{Hegel}^{5}$ : o que fora depositado no divino é transferido para o próprio homem, há uma preocupação em representar a vida material. Como exemplo dessa conjuntura se têm as pinturas renascentistas, voltadas à figuração cada vez mais humana dos deuses e, mais tarde, a pintura holandesa que, como iconografia da sociedade burguesa, ocupa-se da figuração do contingente da vida civil. (HEGEL, 2010, pp. 267-286)

Já no limite entre os séculos de modernismo, chegando a obra às últimas consequências dessa autorreferência, o aspecto da individualidade a circula, sendo esta fruto de um sujeito que, a partir da totalidade, extrai uma percepção particular isolada do todo; trata-se da valorização do ideal de "gênio" (BÜRGER, 2009, p. 109). O gênio do século XX forja uma obra com duas faces contraditórias: por um lado, trata-se de uma forma de resistência à sociedade burguesa, uma via alternativa à Zweckrationalität, a obra como

\footnotetext{
${ }^{4}$ BÜRGER, Peter. Teoria da Vanguarda. Trad. José Pedro Antunes. São Paulo: Cosac Naify, 2008.

${ }^{5}$ HEGEL, G. W. F. O Sistema das Artes. Trad. Álvaro Ribeiro. São Paulo: Martins Fontes, 2010. Cursos de Estética.
} 
manifesto à funcionalidade; por outro ângulo, o condensar dessas ideias oculta as forças contraditórias existentes na sociedade. Afirma Bürger:

Dissociada da práxis vital, na arte podem ter entrada todas aquelas necessidade cuja satisfação é, em razão do princípio de concorrência que prevalece sobre todas as esferas da vida, impossível no dia-a-dia. Valores como humanidade, alegria, verdade são igualmente expurgados da vida real e preservados na arte. A arte tem, na sociedade burguesa, um papel contraditório: ela projeta a imagem de uma ordem melhor, na medida em que protesta contra a perversa ordem existente. Mas, ao concretizar, na aparência da ficção, a imagem de uma ordem melhor, alivia a sociedade estabelecida da pressão das forças voltadas para a transformação. (BÜRGER, 2009, p. 107)

A realidade outra construída pela obra é a resistência através do ocultamento. O potencial transformador existente nas condições sociais - como forças opostas confrontáveis em favor da mudança - é desativado graças ao imagético que opta pelo sonho do mundo ideal e abre mão de um realismo pela ação do conflito. Como apontara Adorno (ADORNO, 1982, p. 15), a obra possui um substrato material e através do plano empírico busca inspiração, porém condensa em sua esfera o que não é aceito no mundo dos objetos e "vive" na qualidade de força contrária, ou seja, sua organicidade depende, necessariamente, de relações de oposição. A arte moderna é então o subterfúgio pelo qual essa idealização da realidade escapa. A obra é conduzida à negatividade: a "subjetividade pura" pretende ser objetiva. $\mathrm{O}$ caráter manifesto da obra se dá pela contestação difusa que reivindica de modo vazio uma transcendência dos limites do sujeito através da constante tentativa de ruptura; ocorre uma superação destrutiva do anterior, de modo que o "moderno" se movimenta apenas para se impor como o mais recente, seu é o desejo de ser o novo. Afirma o autor sobre o Expressionismo:

(...) a falta de ressonância social não foi a única causa de decadência do expressionismo; não é preciso insistir demasiado nesse ponto, a involução das disponibilidades, a totalidade da recusa, termina numa indigência total, no grito ou no gesto irremediavelmente impotente, literalmente no Da-Da. Muda-se em brincadeira tanto a respeito do conformismo como de si mesmo, porque reconhece a impossibilidade da objetivação artística, a qual, no entanto é postulada por toda a manifestação artística, quer queira quer não; sem dúvida, só resta gritar. (ADORNO, 1982, p. 43)

De maneira fetichista, a obra expressionista toma a via do novo, pretende-se como aquilo nunca visto antes que, por consequência, reivindica certa desconexão. Sua experimentação é um teste com a forma a partir do qual, em um dado momento, aparecerá de modo resplendoroso. Essa empreitada traz consigo a intencionalidade de encantar e, assim 
como uma mercadoria, atrair a atenção pela sua simples diferença em relação ao anterior. Escapa-lhe à atenção, entretanto, sua incontornável relação com a totalidade, pois o jogo parte das peças do obsoleto para então aniquilá-lo. O novo não atinge sua pretensão enquanto tal.

Aponta-se para o que é descrito na Dialética Negativa": "Defender o não-idêntico" é manter o paradigma entre os contrários. A “compulsão à identidade" é submissão da diferença à categoria do câmbio, valorar os diferentes até que estes se tornem idênticos. A modernidade assim se apodera da imaginação do artista: a espontaneidade se torna uma regra:

A ideia de liberdade, intimamente ligada à autonomia estética, formou-se na dominação que a generalizava. Também as obras de arte. Quanto mais livres se tornaram dos seus fins exteriores, tanto mais perfeitamente se definiram enquanto organizadas, por sua vez, na dominação. (ADORNO, 1982, p. 29)

Dá-se a "ruptura pela ruptura", já que o moderno se põe à frente meramente em nome da mudança, pela degradação de seu anterior. Essa "nova arte" mediatiza a experiência e, a partir desta, constrói uma porta ao subjetivo dentro do qual se perde. A arte moderna busca, em última instância, uma experiência "ser-para-si" e, ao se constituir como abstração, parece transcender o sujeito. Com a pretensão de estilhaçar a "ilusão do real", cristaliza-se em suas próprias correntes; desse modo, a espontaneidade, outrora uma liberdade na criação, como se afirmou, vem a ser paradoxalmente uma norma. Esse fenômeno é o que Adorno parece caracterizar como "lei do novo": em processo de abandono com o tradicional, a arte de vanguarda é contínuo brincar com os cacos da totalidade na esperança do inédito - ou como se ilustra, com as peças do piano (ADORNO, 1982, p. 45). Esquece-se, então, que as peças que são combinadas são pertencentes àquilo que já foi. A espontaneidade é o mecanismo da lei do novo:

O movimento nessa direção foi violentamente antecipado pela ala extrema dos expressionistas, até o Dada. No entanto, a falta de ressonância social não foi a única causa de decadência no expressionismo; (...) a involução das possibilidades, a totalidade da recusa, termina numa indigência total, no grito ou no gesto irremediavelmente imponente; literalmente no Da-da. Muda-se em brincadeira tanto o respeito do conformismo como de si mesmo, porque reconhece a impossibilidade da objetivação artística, quer queira quer não. Sem dúvida, só resta gritar. (ADORNO, 1982, p. 43)

O grito reivindicado ecoa no vazio, sua manifestação se encontra novamente no ideal da ruptura. Podemos inferir do olhar do jovem Adorno que a obra expressionista realiza com

\footnotetext{
${ }^{6}$ ADORNO, Theodor Wiesengrung. Dialética Negativa. Trad. Carlos Casanova. Rio de Janeiro, Zarah,2009. p.
} 130 
toda sua violência um movimento para fora que obtém como resultado apenas o repousar sobre si; ela tem assim seu paradoxo. Entretanto, antes de um sintoma do moderno (enquanto categoria filosófica), o Expressionismo, à luz da história da arte, parece não se entregar ao falso 'ex' que recai no fatídico centrípeto. Externar-se foi uma de suas consequências, mesmo que seu vir-à-luz não tenha significado de todo um reconhecimento.

\section{Da relação entre obra e história - dissensões com método}

Notar-se-á que, na história da arte, a adjetivação "expressionista" não se refere necessariamente ao movimento do início do século XX. Ela traz consigo a multiplicidade da própria "expressão", que recai sobre períodos consideravelmente distantes entre si. Roger Cardinal $^{7}$ mostra que a expressividade é associada basicamente à espontaneidade do gesto, algo que nos conduziria à firmação da subjetividade em um caráter emergencial:

Aplicado de forma mais incisiva, o termo pode ser referir ao trabalho daqueles artistas ou movimentos que iniciaram uma rebelião contra uma ortodoxia estilística que perdera de vista as fontes do sentimento espontâneo. (...) pode-se atribuir um caráter expressivo à arte barroca, considerada uma erupção flamejante de formas expressivas destinadas a provocar emoções tumultuadas, em contraste com o decoro da arte clássica. Do mesmo modo, a rebelião do romantismo europeu pode ser vista igualmente como uma renovação do princípio expressionista, uma reafirmação do impulso em direção ao imediatismo emocional (enquanto distinto da elaboração secundária ou decoração formal). (CARDINAL, 1988, p.25)

A dificuldade de definir o termo "Expressionismo" não se encontra apenas na generalidade do conceito, mas também na multiplicidade do próprio movimento. Tal foi seu alcance que os diversos grupos surgidos, ao mesmo tempo em que possuem similaridades, diferenciam-se em suas propostas, dada relação entre os artistas e sua dispersão geográfica. A despeito de tais particularidades, Shulamith $\mathrm{Behr}^{8}$ destaca importantes aspectos comuns. A autora assume que, na qualidade de uma vanguarda, teve-se a consciência da época e da necessidade de rompimento com o obsoleto.

Outro ponto é o caráter ideal expressionista ligado à natureza emocional particular que se pensa como expressão da coletividade, já que "no cerne da teoria expressionista residia o paradoxo de que os dilemas pessoais e a expressão do artista, não obstante seu caráter particular e fortemente subjetivo, podiam reavivar noções utópicas de comunidade e

\footnotetext{
7 CARDINAL, Roger. O Expressionismo. Trad. Cristina Barczinski. Rio de Janeiro: Zahar, 1988. (Coleção Cultura Contemporânea)

${ }^{8}$ BEHR, Shulamith. Expressionismo. Trad. Rodrigo Lacerda. São Paulo: Cosac \& Naify, 2000. (Movimentos da Arte Moderna)
} 
identidade espirituais.” (BEHR, 2000, p. 8). O artista, diante da época de declínio, recorre às suas próprias forças, faz desta sua liberdade, que rompe com o institucionalismo que o neutraliza:

Explícita nesse ideário está a crença utópica no poder evolutivo da arte e em seu poder de transformar a sociedade. Implicitamente, porém, ele nos alerta para o fato de que a reivindicação da vanguarda por uma estética abstrata e honesta está muito além da compreensão do gosto contemporâneo. Tais aspirações eram, em boa parte, extraídas da influência intelectual de Friedrich Nietzsche (...) (BEHR, 2000, p.9)

Deste modo, a irrestrição do processo criativo abre mão da racionalidade, que representa a coerção internalizada. $\mathrm{O}$ artista então supera os limites entre sujeito e objeto. Como aponta Cardinal, a maneira como os gestos se dão na pintura denunciam tal aspecto: ainda muito ligados aos resquícios pós-impressionistas (notadamente na figura de Van Gogh), as pinceladas ocorrem de modo veemente (empastadas e violentas). A recepção de Nietzsche - em verdade inspirações artística a partir de leituras livres e descomprometidas - é mais uma contribuição à força do gesto.

Pelo seu caráter múltiplo, que condensa sintomas de uma história prestes a desabar, o Expressionismo surge como a ferida aberta sobre a categoria. No que diz respeito à tentativa de seu desmembramento enquanto conceito, este movimento (que se aproxima muito mais de uma nova forma de pensar a arte) demonstra em grau máximo a lacuna existente entre a obra e método, de modo que a própria crítica que sempre procurou cercar seu objeto também é colocada em questão. Walter Benjamin, em Origem do Drama Barroco Alemão ${ }^{9}$, aponta como a compreensão da obra de arte foi atingida pela crítica na medida em que não foi entendida em sua essência, ou seja, como ideia. O historicismo moderno opera a constante subordinação da obra à categoria visando seu posicionamento no plano contingente. Ocorre que, assim procedendo, põe-se em risco a possibilidade do ser característico da obra de arte. Tal possibilidade se refere a um acesso à totalidade através da obra que a relaciona com aquilo que a antecede e precede, sem necessariamente seguir a sequência supostamente lógica através de uma historiografia:

9 BENJAmin, Walter. Origem do Drama Barroco Alemão. Trad. Sérgio Paulo Rouanet. São Paulo: Braziliense, 1984. 
(...) do mesmo modo que juntas uma série de obras de arte, visando o que elas têm em comum, é um empreendimento visivelmente ocioso, quando não se trata de acumular exemplos históricos ou estilísticos, e sim de determinar a essência dessas obras, é inconcebível que a filosofia da arte renuncie algumas de suas ideias mais ricas, como a do trágico ou a do cômico. (...) Nisso, elas podem ser ajudadas por uma investigação que não procure, desde seu ponto de partida, identificar tudo aquilo que pode ser caracterizado como trágico ou cômico, mas que vise o que é exemplar, ainda que só consiga encontrá-lo em um simples fragmento. (BENJAMIN, 1984, p.66)

O processo pelo qual a obra se dá é então uma transitoriedade rumo ao ponto extremo, quando há um significativo momento de ruptura e ela se apresenta como seu próprio conceito. A justaposição pela observação caracteristicamente empírica - o que, por consequência, constrói o discurso sobre a arte - não a permite lançar-se ao mundo através de sua própria linguagem, o que assola, portanto, o entendimento da ideia inserida em sua constelação. Afirma Benjamin:

Essa investigação não fornece "critérios" para o autor de resenhas. Nem a crítica nem os critérios de uma terminologia - o teste de uma teoria filosófica das ideias, na arte - podem constituir-se segundo o critério externo da comparação, mas de forma imanente, pelo desenvolvimento da linguagem formal da própria obra, que exterioriza seu conteúdo, ao preço de sua eficácia. (BENJAMIN, 1984, p.67)

Constituir o método que leve em consideração a ideia à qual a obra ascende é uma atividade essencialmente reflexiva, uma vez que o pensamento se volta ao próprio fenômeno e permite que este se apresente como um reflexo da totalidade, uma unidade com um universo interior a partir do qual as demais ideias podem ser acessadas. Trata-se, em última instância, de uma obra que é externada por seu próprio substrato espiritual. $\mathrm{O}$ autor aponta que tal compreensão ocorre como a monadologia (teoria formulada por Gottfried Leibniz no século XVII) que justifica, por exemplo, a conexão remota entre dois corpos distantes. Assim como o autor moderno afirmara que a partir da mônada se pode conhecer o universo e que aquelas estão ligadas de um modo não atestável empiricamente, as ideias, para Benjamin, se relacionam em seu âmbito supra-histórico, de modo que cada uma se mostra como porta à infinitude:

A ideia é mônada. O Ser que nela penetra com sua pré e pós-história traz em si, oculta, a figura do restante do mundo das ideias, de mesma forma que, segundo Leibniz, em seu Discurso sobre a Metafísica, de 1686, em cada mônada estão indistintamente presentes todas as demais. A ideia é mônada - nela reside, preestabelecida, a 
representação dos fenômenos, como sua interpretação objetiva. (....) Assim o mundo real poderia constituir uma tarefa, no sentido de que ele nos impõe a exigência de mergulhar tão fundo em todo o real, que ele possa revelar-nos uma interpretação objetiva do mundo. $\mathrm{Na}$ perspectiva dessa tarefa, não surpreende que o autor da Monadologia tenha sido também o criador do cálculo infinitesimal. A ideia é mônada - isto significa, em suma, que cada ideia contém a imagem do mundo. A representação da ideia impõe como tarefa, portanto, nada menos que a descrição dessa imagem abreviada do mundo. (BENJAMIN, 1984, p.69)

Entendida em sua ideia, a obra de arte não é o conceito construído de um diálogo a partir de fora: é em um momento emergencial em que ela virá à tona e forjará sua categoria, tornar-se-á por si mesma um “exemplar", na terminologia do autor. De outro modo, seu conteúdo é ameaçado ou até mesmo perdido. Essa perspectiva vai ao encontro da sentença lançada por Adorno décadas mais tarde: “A arte só é interpretável pela lei de seu próprio movimento, não por invariantes." (ADORNO, 1982, p.12).

Do mesmo modo, falar de uma origem dedutível também é uma incompatibilidade com a unidade da obra. Adorno aponta que lhe é característico um constante processo de autoconstrução, no qual ela busca sua legitimação numa espécie de hit et nunc, e que, na continuidade de seu mover-se, sempre é iniciada a busca por uma nova identidade, de modo que o firmamento da obra enquanto tal não é dado pelas determinantes - ou ainda pelo cânone -, mas pelas possibilidades do que ela poderá ser.

A arte tem seu conceito na constelação de momentos que se transformam historicamente; fecha-se assim à definição. A sua essência não é dedutível de sua origem, como se o primeiro fosse um fundamento, sobre o qual todos os seguintes se erigem e desmoronam logo que são abalados. A crença segundo a qual as primeiras obras de arte são as mais elevadas é romantismo tardio; com não menor direito poder-se-ia sustentar que as primeiras obras com caráter artístico (...) são confusas e impuras. (ADORNO, 1982, p.12)

Walter Benjamin já fizera uma importante diferenciação de "origem" em relação a "gênese" angular a Adorno. "Origem" não se trata de um momento cronologicamente cristalizado, mas do conflito entre a essência e o plano histórico. Ela é constituída a partir de tal relação que legitimará historicamente a ideia, sendo esta aberta simultaneamente ao anterior e ao posterior. Assim, ainda que como um núcleo, a origem participa na continuidade constituindo-se e, ao mesmo tempo, se modificando. Se a gênese é estacionária, a origem é o resultado do vir-a-ser, isso porque demonstra as mudanças nas relações que temos com a ideia: 
O termo origem não designa o vir-a-ser daquilo que se origina, e sim algo que emerge do vir-a-ser e da extinção. A origem se localiza no fluxo do vir-a-ser como um torvelinho, e arrasta em sua corrente o material produzido pela gênese. $\mathrm{O}$ originário não se encontra nunca no mundo dos fatos brutos e manifestos, e seu ritmo só se revela a uma visão dupla, que o reconhece, por um lado, como restauração completo e inacabado. Em cada fenômeno de origem se determina a forma com a qual uma ideia se confronta com o mundo histórico, até que atinja a plenitude na totalidade de sua história. A origem, portanto, não se destaca dos fatos, mas se relaciona com sua pré e póshistória. As diretrizes da contemplação filosófica estão contidas na dialética imanente à origem. (BENJAMIN, 1984, p.68)

Compreender a obra através da relação com sua ideia é uma via à atemporalidade do Expressionismo. Conforme identifica o autor, o movimento apresenta aspectos similares ao Barroco do século XVII, no qual se fazia presente a vontade artística ante uma época de decadência. Ambos também possuem a característica de identidade nacional, uma busca pelo regional, uma espontaneidade a partir da qual há a construção de uma linguagem própria que se impõe ao mundo. Esse esforço aponta para a constituição de um caráter humano in natura, tal como um reflexo ideal de um homem anterior ao construto moral:

As obras pacifistas de hoje, com sua ênfase sobre a simple life e a bondade natural do homem, contrapõem-se da mesma forma que o teatro pastoral, na era barroca, ao romance político, ao qual se dedicaram autores prestigiosos, tanto no período barroco, como em nossos dias. (BENJAMIN, 1984., p.78)

Ainda que se refira à literatura, a afirmação é bastante apropriada para o que se observou nas artes visuais. Uma das principais motivações entre os artistas é o retorno à natureza através de cenas opostas ao cotidiano citadino ${ }^{10}$. As paisagens, evocando o "querer artístico", figuram repulsa ao intelectualismo, de modo que o homem não vise uma reflexão teórica sobre si, mas conceba a si mesmo. Respondendo ao que Benjamin aponta, a obra expressionista é, de fato, um momento de ruptura. Em uma época de decadência - assim como também ocorreu no Barroco -, a crítica de arte não alcança seu objeto recorrendo à

\footnotetext{
10 Sobre tal aspecto, afirma Shulamith Behr: "Na medida em que seus trabalhos evocavam as tendências correntes na vida moderna, a "natureza" é que se tornava impregnada de associações contemporâneas. Enquanto cenas urbanas enfocavam a expansão industrial e o dinamismo comercial e recreativo da cidade, suas paisagens rurais introduziam o debate sobre os valores da vida ao ar livre ou, por exemplo, de um banho de sol sem roupa."
} 
significação, tendo em vista o decifrar. Escapando pelas frestas da categoria, a arte da época demonstra mais veementemente que sua chave é sua própria ideia, já que esse pressuposto, conforme já se afirmou, revela a inserção da obra na totalidade. Não se trata de um processo decorrente da dinâmica da história natural, porém, novamente, das relações entre as ideias.

Esse é o sinal dos tempos: não se pode descobrir nenhum estilo novo, nenhuma tradição popular desconhecida, que não apele imediatamente, e com total evidência, para a sensibilidade dos contemporâneos. Essa fatídica sugestibilidade psicológica, pela qual o historiador, por um processo de substituição, procura colocar-se no lugar do criador, como se este, por ter criado a obra, fosse seu melhor intérprete, recebeu o nome de empatia, que mascara a simples curiosidade como o disfarce do método. (BENJAMIN, 1984, p.76)

Mesmo "pensar como" o artista - o que suscitaria uma leitura a partir da intencionalidade - é uma empreitada falha já que, a partir de sua gênese, essa mesma obra é responsável por instaurar sua relação entre passado e futuro. A dificuldade em se apreender sua essência através da categoria se dá justamente porque as características dos gêneros escapam a eles próprios, atravessam épocas e unem movimentos separados pelos séculos. Classificar é inevitavelmente retirar do movimento sua continuidade. Assim, a ideia "barroca" se une à ideia "expressionista".

\section{O movimento em contexto}

Através de uma inevitável abordagem cronológica sobre a obra pictórica, percebemos como os desdobramentos do Expressionismo foram fundamentais para a inconsistência que tange ao debate. O grupo "Brücke" é fundado em 1905 na cidade de Dresden. Cronologicamente próximo ao início do movimento, seus integrantes estavam profundamente influenciados pelo ideal da liberdade artística que pretende a autenticidade através da imediatez, na tentativa de captar o gesto mais puro e inicial. Os quatro membros iniciais eram estudantes da arquitetura que, na busca por processos alternativos, optam por certo distanciamento da técnica estritamente acadêmica. Um recurso muitas vezes utilizado era o desenho instantâneo logo no primeiro olhar, a captação rápida. A dinâmica seria converter a impressão em expressão, o que justifica, por exemplo, a larga utilização da xilogravura nos trabalhos. Dube ${ }^{11}$ aponta que a necessidade de preservar esse impulso mais verdadeiro é a tentativa de forjar da identidade artística independente. Delineia-se, de alguma forma, uma crítica ao institucionalismo: 
Como pintores, eles podiam seguir uma linha mais subjetiva de que como arquitetos. Mostravam uma enorme dedicação pela sua pintura e não toleravam o ensino. Queriam conservar a frescura e a pureza das suas sensações, tal como a força e a honestidade das suas visões. A força de vontade e confiança em si mesmo e a exigência que eles se impunham e ao mundo em geral deu-lhes a energia para determinarem os seus próprios fins, rejeitando tanto os ideais como as perfeições tradicionais. Concebiam a arte com uma "criação original" e não como uma técnica; segundo eles, e o fim a alcançar é qualquer coisa que não se ensina. (DUBE, 1976, p.27)

Há uma motivação ao encontro com a natureza. Em um processo semelhante ao Romantismo, ocorre um desejo de proximidade à organicidade natural, com a qual se sela um contato. É comum na obra de Ernst Kirchner paisagens na beira de lagos (geralmente nas proximidades de Dresden) com nus à grama e próximos a árvores.

Tomemos um dos integrantes do Brücke, Karl Schmidt-Rottluff. Um exemplo dos procedimentos mais comumente adotados pelo pintor é Curva de Parque ${ }^{12}$, de 1910: merecem destaque as diferenças vagas entre os planos; sombreados escuros fornecem alguns limites ao mesmo tempo em que se perdem na própria paisagem; os arbustos se confundem com o fundo e convergem para um ponto de fuga; profusões em tons de vermelho e laranja formam a estrada e, à direita, sugere-se uma construção; à esquerda, riscos vermelhos contrastam com azul e verde de modo a tornar pulsante a relação entre as cores. A imagem é um convite à distorção.

Outro membro, Emil Nolde, cujas obras foram recusadas em templos religiosos devido a sua abordagem, recorre à pulsão típica do homem e, ao mesmo tempo em que valoriza o aspecto religioso, insere a exaltação. Karl Schmidt-Rottluff, em semelhante pretensão, joga com a aparência, utiliza as cores como uma resposta à percepção e concebe uma materialidade sentimental.

Esses vários pontos que unem e afastam os artistas de uma possível similaridade são uma herança da maneira como as vanguardas históricas se iniciam na Alemanha. Em uma oposição de motivação política ao final do século XIX, surgem as chamadas "secessões" uniões menores nas quais se cultivava um desacordo com o caráter conservador da arte imperial. (DUBE, 1976, p. 8) Esses pequenos grupos procuravam inicialmente uma interação com a arte impressionista francesa. A necessidade de transição entre fronteiras a que os vanguardistas se propunham possui um significado mais amplo. No Brücke, é comum recorrer à gravura medieval alemã e, paralelamente, há uma exploração de técnicas desenvolvidas nos

\footnotetext{
${ }^{12}$ Tradução livre para "Parkecke".
} 
longínquos contextos da Oceania e da África. As viagens de Paul Gauguin ao Caribe e ao Taiti são uma importante motivação para a dissolução das fronteiras e a descentralização na concepção tipicamente europeia. Essas vias pelas quais os expressionistas escapam do engessamento institucional do processo artístico é um dos sintomas daquilo que Cardinal parece apresentar como o perspectivismo que fragmenta a ideia do universal. Um sujeito que pensa pela coletividade (tônica mais presente no Cavaleiro Azul) não é simplesmente particularidade, mas perspectiva ${ }^{13}$.

Corroborando com esse aspecto, a atitude aponta para um contato suprassensível por sobre a materialidade. $\mathrm{O}$ mundo apresenta meandros que não estão claros aos nossos olhos (remetendo à noção romântica já apontada). É depositado então um caráter místico naquilo que não é apreendido diretamente, e que a obra expressionista seja uma interação com a superfície que encobre a realidade. Em uma ponte estabelecida pelo autor, há uma relação com as descobertas científicas:

A realidade física, portanto, só poderia ser verificada por meio de instrumentos que já não eram capazes, como fora o microscópio, de oferecer uma imagem das texturas celulares dos organismos, mas apenas registravam coisas tais como impulsos, ondas e ondulações (...) Uma vez que os cientistas estavam relacionando-se com a natureza "invisível" em termos de matemática, o artista precisa também ajustar sua linguagem. Dessa forma, uma mudança fundamental ocorre na natureza do signo pintado. Passa a não ser mais suficiente registrar a impressão direta de uma forma visível derivada da natureza. Era preciso que a arte desenvolvesse o equivalente ao código simbólico da matemática, para traduzir as instituições da organicidade que haviam agora se tornado invisíveis. (CRADINAL, 1988, p.77)

Wassily Kandinsky é um exemplo dessa conjuntura. Seu abstracionismo chega ao geométrico, o que aponta para outra realidade (de caráter místico); essa divisão entre dois modos de se ter o mundo - físico e não físico - é um rompimento com o naturalismo. O uso da cor entre os membros do Blaue Reiter também será um importante indicativo: há uma relação de oposição entre o azul masculino espiritual e o feminino amarelo e terreno, sendo

13 R. Cardinal aponta motivações para esse desenvolvimento, sendo algumas dessas muitas vezes formas de leituras por parte dos artistas. Essa recepção, entretanto, não caracterizaria em muitos casos uma análise teoricamente apropriada, haja vista que, no contexto dos artistas, não lhes ocorria uma intencionalidade exegética. Lista o autor: "Entre estes estariam o anúncio perturbador da morte de Deus feito por Nietzsche e a visão consequente da paisagem ética do homem sendo despojado de todas as referências; o lema relatividade derivado da física (Mach, Einstein), agora aplicada à esfera psicológica e moral para sugerir aniquilação de todos os absolutos; (...) a correlação sedutora da expressão artística com desordem mental, tal como foi apresentada pelo estudo de Cesare Lombroso, Gênio e loucura; o colapso do modelo integrado da psique individual da psicanálise, para não falar do aparecimento de uma estética de choque derivada da decadência francesa (Baudelaire, Rimbaud e seus sucessores)." (CARDINAL, 1988, p.44) 
este a materialidade. Assim, existirá no grupo uma dinâmica semelhante àquela observado no Brücke, entretanto suas questões buscarão uma fundamentação mais espiritual e inevitavelmente controversa.

Criado por ex-membros da Neue Küntlervereinigung München (União dos Artistas de Munique), o Cavaleiro Azul parece oferecer uma resposta mais efetiva a um possível caráter supra-histórico. Se no Brücke existira um impulso para descentralizar uma concepção existencial há muito vigente rompendo fronteiras culturais, o segundo grupo voltava às origens. Kandinsky manteve grande preocupação em resgatar elementos campesinos e rústicos de seu país; da mesma forma, os alemães Franz Marc e Gabriele Münter - que fora por muito tempo companheira de Kandinsky - aplicaram muitos aspectos da cultura bávara em seus quadros. Ainda que fossem muito ligados ao que se chamaria de "pesquisa" no processo criativo, uma notável veia crítica independente atravessou suas atividades. Murnau, centro comercial de destaque próximo a Munique, foi um grande estímulo para paisagens que, em um progressivo ganho de abstração, revelavam um mundo agora inegavelmente diverso. Por parte do pintor russo, as cores e os planos em suas composições ocorrem como um acesso ao significado por meio de curvas e traços. Franz Marc, que possuía como mote de seu trabalho figuras animais, cria um mundo em cujo acesso nos vemos obrigados a uma transfiguração do olhar . Gabrielle Münter, no início notadamente influenciada por Kandinsky, liga-se ao ideal também através do geométrico; mais tarde, porém, suas telas ganham cores mais escuras e contornos mais definidos, o que revela sua ocupação em relatar uma realidade dramática afetada pela flutuação econômica (BEHR,2000, p. 36). Cardinal justifica que o rompimento dos limites, sejam eles culturais ou históricos, é o que caracteriza a utopia, e esse movimento aponta para uma visão além das aparências. É através da superfície que adentramos a essência do mundo:

A visão utópica é aquele que busca superar as limitações das circunstâncias, pondo em evidência uma realidade que está além do imediato. Nesse sentido, o Expressionismo faz um esforço para escapar à história e é essa sua forma de resistência (CARDINAL, 1988, p.60)

Conforme o autor ainda sustenta, há um esforço em romper inclusive os limites do próprio "eu" (CARDINAL, 1988, p.65), o que leva àquele propósito de uma individualidade que se comporta como o todo. $\mathrm{O}$ artista não está preocupado meramente em mostrar suas próprias percepções, mas ele visa corresponder às exigências sentimentais de um grupo maior 
ao qual ele pertence. Entretanto, essa característica constitui uma fratura do Expressionismo. Analisemos:

\begin{abstract}
Anunciando uma prática comum no período expressionista, Strindberg designa um ou dois personagens por seu primeiro nome, mas refere-se aos outros genericamente como "O Oficial", "O Pai", "O Porteiro", "O Poeta", e assim por diante. Pessoas distintas passam a ser, consequentemente, a mesma pessoa, diversidade confunde-se com identidade, de acordo com a concepção do escritor de "personagens sem persona", que são as invenções de uma consciência global. (CARDINAL, 1988, p. 40)
\end{abstract}

Aquilo que o autor aponta como a confusão entre diversidade e identidade é uma falha da história refletida no sujeito. A posição do personagem não caracteriza a inserção de um indivíduo na narrativa, porém indica uma "abertura" a qualquer denominação possível. De certo modo, não se pode falar em "sujeito", ou ainda nos termos de Adorno, não se configura uma "vivência":

\begin{abstract}
A imagem do mundo, contrária à representação do Eu (Ich-Abbild), permanece representação (Abbild) do Eu projeto sobre o mundo, não um típico teor de vivência (Erlebnisinhalt). Tão logo, a vontade expressionista vinda de um polo permanece lírica, entrega o mundo ao lustroso salão da alma, inunda com uma inegável luz. Toda via, onde a corrente do produzir busca indução através da pluralidade, acumula-se a dualidade, aspira-se o drama. (ADORNO, 2004, p.610)
\end{abstract}

A permanência na abertura a qualquer identidade se dá pelo caminho da incompletude da obra, ou seja, o personagem que pode ser qualquer outro - ou ainda que, em certo sentido, deseja ser quaisquer outros - é o sujeito que não está em um Erlebnis ${ }^{14}$, mas que se encontra no drama autorreferenciado, um jogo consigo mesmo.

A arte de vanguarda é, por seu movimento, um paradoxo: por um lado, o conceito da obra sofre dissolução; os limites que demarcavam sua posição na totalidade foram abalados irreversivelmente; investigar o que é arte requer, a partir desse momento, a passagem pela incurável fissura de possibilidades até então desconhecidas que não asseguram sua existência. Por outro lado, o conflito latente que se externa no início do século XX revela uma "nova concepção": não se trata de um fim propriamente, porém um obscuro limiar da incompatibilidade seja com a história, seja com a crítica sobre o objeto. Trata-se de um limite a partir do qual o processo ganha progressiva importância em relação à obra enquanto

14 Optamos na presente tradução pelo termo "vivência". Erlebnis, porém, refere-se, na linguagem corrente, a uma experiência significativa à qual se atribui um sentido emocional. "Vivido" pode ser também um equivalente ao termo. 
resultado. O caso específico do Expressionismo, como se observou, é modo de compreender esse espírito. O jogo com o real, o rompimento das fronteiras e o perspectivismo não configuram o estilhaçamento da arte, mas um modo de relação com o mundo já fragmentado. Uma de suas tentativas foi corresponder a essa história em crise, sua busca por recolocar a realidade cria lacunas vertiginosas. Sua espontaneidade que, pela força que a direciona contra o mundo, desequilibra-se de certo modo em irracionalidade, fornece ao artista o poder de autossuperação que parece escapar-lhe às próprias mãos. Pode-se assim deduzir a marca impressa pelo movimento sobre a história da arte. Esses fatos possivelmente não revelaram as ideias, tornaram-nas mais enigmáticas. A obra de arte se tornou gradativamente parcialidade. Em criações vindouras, esses estalidos da fragmentação do que um dia já foi far-se-ão ouvidos além do bidimensional.

\section{Referências bibliográficas}

ADORNO, Theodor Wiesengrund. Dialética Negativa. Trad. Carlos Casanova. Rio de Janeiro, Zarah, 2009.

Comunicação)

Teoria Estética. Trad. Artur Mourão. Lisboa: Edições 70, 1970. (Arte e

Expressionismus und künstliche Wahrhafitgkeit. In: Gesammelte Schriften. Frankfurt: Surhkamp, 2004;

BEHR, Shulamith. Expressionismo. Trad. Rodrigo Lacerda. São Paulo: Cosac \& Naify, 2000. (Movimentos da Arte Moderna);

BENJAMIN, Walter. Origem do Drama Barroco Alemão. Trad. Sérgio Paulo Rouanet. São Paulo: Braziliense, 1984;

BÜRGER, Peter. Teoria da Vanguarda. Trad. José Pedro Antunes. São Paulo: Cosac Naify, 2008;

CARDINAL, Roger. O Expressionismo. Trad. Cristina Barczinski. Rio de Janeiro: Zahar, 1988. (Coleção Cultura Contemporânea);

DUBE, Wolf-Dieter. O Expressionismo. Trad. Ana Isabel Medonza y Arruda. São Paulo: Verbo, 1976.

HEGEL, G. W. F. O Sistema das Artes. Trad. Álvaro Ribeiro. São Paulo: Martins Fontes, 2010. Cursos de Estética. 